\title{
Nutshells as Modifiers of Carbon Paste Electrodes Used in Detecting Chloroorganic Water Pollutants
}

\author{
Katarzyna Skrzypczyńska, ${ }^{a}$ Krzysztof Kuśmierek, ${ }^{a}$ Andrzej Świątkowski, ${ }^{a}$ \\ Lidia Dąbek, ${ }^{\mathrm{b}, *}$ and Ilona Piros ${ }^{\mathrm{a}}$

\begin{abstract}
Electrochemical properties of a carbon paste electrode (graphite) modified with hazelnut and walnut shells were investigated. The adsorption of 4chlorophenol (4-CP) on the studied materials was determined, and the hazelnut shells were found to provide a higher adsorption capacity. The hazelnut and walnut shells were used to modify the carbon paste electrode to detect $4-\mathrm{CP}$ by cyclic voltammetry. Compared to an unmodified electrode, all of the new paste electrodes showed much higher sensitivity in the 4-CP detection.
\end{abstract}

Keywords: 4-Chlorophenol; Adsorption; Nutshells; Carbon paste electrode; Voltammetry

Contact information: a: Military University of Technology, Faculty of Advanced Technologies and Chemistry, Kaliskiego 2, 00-908 Warszawa, Poland; b: Kielce University of Technology, Faculty of Environmental, Geomatic and Energy Engineering, al. Tysiaclecia Państwa Polskiego 7, 25-314 Kielce, Poland; *Corresponding author: ldabek@tu.kielce.pl (L. Dąbek)

\section{INTRODUCTION}

Advances in technologies leading to the improvement of the quality of life are often associated with the introduction of processes using environmentally unfriendly chemicals. Therefore, industrial plants can be an important source of environmental pollution (Czaplicka 2004). Over recent decades, the presence of certain compounds with carcinogenic or mutagenic properties in industrial wastewater has become increasingly important for environmental scientists. These substances, even at low levels, can cause harmful effects on the environment and pose a noticeable threat to human health (Gan et al. 2016). Among these substances are phenols, especially chlorinated ones, which are widely used as preservatives in the wood industry and as intermediates in the production of pesticides and adhesives (Wei et al. 2014). In addition, chlorophenols are resistant to biodegradation due to the presence of chlorine atoms connected to an aromatic ring, which means that they remain in water and soil for a long time (Khanikar and Bhattacharyya 2013).

Due to the toxicity of phenol and its derivatives, their presence in the environment is a serious problem requiring urgent action. For this reason, numerous different methods including biological, chemical, and physical processes have been proposed. Among them, adsorption seems to be the most popular and the most frequently used (Ahmaruzzaman and Sharma 2005; Dąbrowski et al. 2005; Hameed et al. 2008; Lin et al. 2009; Noorimotlagh et al. 2015). Therefore, many different adsorbents have been proposed and described. They include activated carbons and other carbonaceous materials, silica materials, and various non-conventional, low-cost materials that have attracted a recent growing interest and popularity. The low-cost sorbents are easily available and disposable without regeneration. They can be classified as natural and biological materials, waste materials including household wastes, industrial wastes, agricultural products, and natural materials including 
sea materials, soil and ore materials (Lin et al. 2009; Soto et al. 2011; Zhou et al. 2015).

For researchers dealing with the environment, both research and the development of selective and rational methods for the detection and determination of phenols are of increasing importance (Das et al. 2014). There are many methods based on chromatographic techniques, capillary electrophoresis (Almeda et al. 2007; Fan et al. 2015; Saraji and Ghani 2015), and spectroscopy (Mukdasai et al. 2016). However, all these techniques have some disadvantages, such as preparation time, high costs, solvents and reagent consumption, and the need for well-trained analysts (Amiri et al. 2012). Currently, it is preferable to search for alternative, non-classical methods that could be simple, fast and clean, taking into account, for example, the principles of green chemistry (Gałuszka et al. 2013).

In this context, electrochemical sensors, e.g., carbon paste electrodes (CPE), are excellent devices used for initial analysis (Cao et al. 2014). They require minimal sample preparation, they are easy to modify, and they are useful for collecting data. In addition, they are sensitive, require a small amount of the sample, and the analysis is carried out quickly and is characterized by high selectivity (Oliveira et al. 2014).

There are currently few reports on the determination of chlorophenols by means of sensors due to difficulties and the fact that they have the ability to generate intermediates covering the surface of the electrode with a thin film. As a consequence, the surface of the sensor becomes passivated. In recent years, attention has been focused on alternative cheap adsorbents of natural origin, i.e., biological or mineral (Mojica et al. 2007; Gómez et al. 2011; Devnani and Satsangee 2013; Elroby 2015; Dar et al. 2016). Generally, these materials are easily available. In this work, carbon paste electrodes modified with hazelnut shells (HS) and walnut shells (WS) for the detection of 4-chlorophenol (4-CP) in an aqueous environment are produced.

\section{EXPERIMENTAL}

\section{Materials and Research Methodology}

The 4-chlorophenol (>99\%) used in the electrochemical studies was obtained from Sigma (St. Louis, USA). The hazelnut shells (Corylus avellana) and walnut shells (Juglans regia) were selected as modifiers of the carbon paste electrodes.

The nutshells were first crushed and then milled in a mixer. Then, they were put through a $2.0 \mathrm{~mm}$ sieve and then through a $1.0 \mathrm{~mm}$ sieve. In the experiments, fractions with a grain size in the range of 1.0 to $2.0 \mathrm{~mm}$ were used (with an average size of about 1.5 $\mathrm{mm}$ ). Before use, all of the modifiers were thoroughly washed with deionized water and dried in a vacuum oven at $130{ }^{\circ} \mathrm{C}$ until they reached a constant weight.

Scanning electron microscope (SEM) photos of these materials were taken at the same magnification using a Philips XL30/LaB6 SEM (Amsterdam, Netherlands). The chemical composition of their surface was also determined using energy dispersive (EDS) X-ray microanalysis. The BET surface area of the nutshells was calculated based on the low temperature $\mathrm{N}_{2}$ adsorption data obtained using a Gemini 2360 analyzer (Micromeritics, Norcross, GA, USA). For the adsorption and electrochemical studies, the tested materials were stored in a desiccator until they were used.

Sorption of 4-chlorophenol with $0.1 \mathrm{~mol} / \mathrm{dm}^{3}$ of $\mathrm{Na}_{2} \mathrm{SO}_{4}$ solution on the HS and WS shells was investigated at various initial adsorbate concentrations in the range of 0.05 to $0.5 \mathrm{mmol} / \mathrm{dm}^{3}$.

The tests were conducted in Erlenmeyer flasks. In the flasks, $0.04 \mathrm{dm}^{3}$ of the $4-\mathrm{CP}$ 
solutions of an appropriate concentration and $1 \mathrm{~g}$ of adsorbent (either hazelnut or walnut shell) were introduced. The contents of the flasks were shaken at $200 \mathrm{rpm}$ at $25^{\circ} \mathrm{C}$. After $24 \mathrm{~h}$, the solution samples were filtered and analyzed for 4-chlorophenol content. The adsorbate concentration in the solution was determined spectrophotometrically (Varian, Carry 3E spectrophotometer, Palo Alto, USA).

The adsorption capacity of 4-CP on nutshells $\left(q_{\mathrm{e}}\right)$ was calculated from the dependence using Eq. 1,

$$
q_{e}=\left(C_{0}-C_{\mathrm{e}}\right) V / m
$$

where $q_{\mathrm{e}}$ is the amount of adsorbate adsorbed on the surface of the adsorbents $(\mathrm{mmol} / \mathrm{g})$, $C_{0}$ is the initial concentration of $4-\mathrm{CP}$ in solution $\left(\mathrm{mmol} / \mathrm{dm}^{3}\right), C_{\mathrm{e}}$ is the equilibrium concentration after $24 \mathrm{~h}\left(\mathrm{mmol} / \mathrm{dm}^{3}\right), V$ is the volume of the solution $\left(\mathrm{dm}^{3}\right)$, and $m$ is the mass of the nutshells $(\mathrm{g})$.

The adsorption kinetic studies were conducted in shaken Erlenmeyer flasks at room temperature for initial 4-CP concentration of $0.2 \mathrm{mmol} / \mathrm{dm}^{3}$. Samples were continually taken from the solution at given intervals and analysed. The adsorbed $4-\mathrm{CP}\left(q_{\mathrm{t}}, \mathrm{mmol} / \mathrm{g}\right)$ was calculated by following equation,

$$
q_{\mathrm{t}}=\left(C_{0}-C_{\mathrm{t}}\right) V / m
$$

where $q_{\mathrm{t}}$ is the amount of 4-CP adsorbed onto adsorbent at time $t(\mathrm{mmol} / \mathrm{g}), C_{0}$ and $C_{\mathrm{t}}$ are the initial concentration $\left(\mathrm{mmol} / \mathrm{dm}^{3}\right)$ and concentration at time $t\left(\mathrm{mmol} / \mathrm{dm}^{3}\right)$, respectively, $m$ is the mass of the adsorbent $(\mathrm{g})$, and $V$ is the volume of the solution $\left(\mathrm{dm}^{3}\right)$.

From the prepared materials, carbon paste electrodes were made with two content modifiers of $5 \mathrm{wt} . \%$ and $10 \mathrm{wt} . \%$ in a mixture with graphite. The pastes were prepared by grating a mixture of powdered graphite (Sigma) with the addition of a modifier in an agate mortar, and then adding the appropriate amount of paraffin oil (Nujol) until a homogeneous consistency was obtained. The resulting pastes were conditioned for $72 \mathrm{~h}$ in a desiccator. After this time, small portions of the paste were placed in the hollow of a Teflon electrode body, lightly compacted, and then polished on smooth paper to smooth the surface. Voltammetric measurements were collected using an AutoLab analyzer (Eco Chemie B.V., Utrecht, Netherlands) equipped with a PGSTAT 20 potentiometer coupled to a computer with GPES version 4.9 software.

A three-electrode system was used, where the working electrode was a carbon paste electrode, the reference electrode was a saturated calomel electrode (SCE), and the counter electrode was a platinum wire. Voltammetric tests were performed for various concentrations of 4-chlorophenol solution (in the range of 0.1 to $0.5 \mathrm{mmol} / \mathrm{dm}^{3}$ ) in 0.1 $\mathrm{mol} / \mathrm{dm}^{3}$ sodium sulphate. During all measurements, the following parameters were maintained: the scan rate was $50 \mathrm{mV} / \mathrm{s}$, the potential of the working electrode was $50 \mathrm{mV}$, the potential pulse amplitude was $25 \mathrm{mV}$, and the potential step was $5 \mathrm{mV}$.

\section{RESULTS AND DISCUSSION}

\section{Nutshells Characterization}

To compare the surface of the shells of both kinds of nuts, SEM (100x magnification) pictures were taken and are shown in Fig. 1. The results of EDS analysis for hazelnut and walnut shells are presented in Table 1. SEM-EDS analyses showed large amounts of $\mathrm{C}$ and $\mathrm{O}$ (comparable for both analyzed materials), and then about 20 times smaller but also comparable amounts of $\mathrm{Ca}$ and $\mathrm{K}$. Other predominant elements in hazelnut 
shells were $\mathrm{S}, \mathrm{P}, \mathrm{Si}$, and $\mathrm{Mg}$. Small amounts of $\mathrm{Fe}$ and $\mathrm{Cu}$ were also found in walnut shells, although these were much higher than their contents in hazelnut shells.

Table 1. EDS Analysis for the Tested CPE Modifiers

\begin{tabular}{|c|c|c|c|c|c|c|c|c|c|c|c|}
\hline \multirow{2}{*}{$\begin{array}{c}\text { Hazelnut } \\
\text { shells }\end{array}$} & \multicolumn{10}{|c|}{ Content (wt\%) } \\
\cline { 2 - 14 } & $\mathrm{C}$ & $\mathrm{O}$ & $\mathrm{K}$ & $\mathrm{Ca}$ & $\mathrm{Mg}$ & $\mathrm{S}$ & $\mathrm{Cl}$ & $\mathrm{Si}$ & $\mathrm{P}$ & $\mathrm{Fe}$ & $\mathrm{Cu}$ \\
\hline $\begin{array}{c}\text { External } \\
\text { surface }\end{array}$ & 52.8 & 41.5 & 2.27 & 2.10 & 0.06 & 0.12 & 0.11 & 0.16 & 0.07 & 0.24 & 0.43 \\
\hline Cross-section & 54.9 & 44.4 & 0.16 & 0.04 & 0.06 & - & - & 0.06 & - & 0.07 & 0.18 \\
\hline Inner surface & 51.6 & 43.2 & 2.02 & 1.81 & 0.10 & 0.12 & 0.09 & 0.18 & 0.07 & 0.29 & 0.39 \\
\hline Walnut shells & \multicolumn{10}{|c|}{ Content (wt\%) } \\
\cline { 2 - 15 } & $\mathrm{C}$ & $\mathrm{O}$ & $\mathrm{K}$ & $\mathrm{Ca}$ & $\mathrm{Mg}$ & $\mathrm{S}$ & $\mathrm{Cl}$ & $\mathrm{Si}$ & $\mathrm{P}$ & $\mathrm{Fe}$ & $\mathrm{Cu}$ \\
\hline $\begin{array}{c}\text { External } \\
\text { surface }\end{array}$ & 49.3 & 43.2 & 1.20 & 3.17 & 0.86 & 0.16 & - & 0.08 & 1.86 & - & - \\
\hline Cross-section & 54.8 & 44.5 & 0.25 & 0.17 & 0.06 & - & - & 0.05 & - & - & 0.04 \\
\hline Inner surface & 54.7 & 39.7 & 1.82 & 2.23 & 0.42 & 0.63 & 0.14 & 0.21 & 0.24 & 0.02 & - \\
\hline
\end{tabular}

The nutshells were subjected to elemental analysis (Table 2). The results for $\mathrm{C}$ and $\mathrm{O}$ in the shells of both types of nuts were similar for both test methods (Tables 1 and 2). Some minor differences may have resulted from the differences in the EDS method (surface layer testing) and elemental analysis (for the whole sample mass by the combustion method).

The specific surface areas for hazelnut and walnut shells were 8.5 and $7.1 \mathrm{~m}^{2} / \mathrm{g}$, respectively. These values are low but comparable with the results reported by other authors (Kuśmierek and Świątkowski 2015a; Şencan et al. 2015; Tang et al. 2017). For example the $S_{\mathrm{BET}}$ of the hazelnut shells was $5.92 \mathrm{~m}^{2} / \mathrm{g}$ (Şencan et al. 2015) and the surface area of the walnut shells ranged from 1.01 to $3.12 \mathrm{~m}^{2} / \mathrm{g}$ (Tang et al. 2017).

Table 2. Elemental Analysis for the Tested CPE Modifiers

\begin{tabular}{|c|c|c|c|c|}
\hline \multirow{2}{*}{ Material } & \multicolumn{4}{|c|}{ Content (wt.\%) } \\
\cline { 2 - 5 } & $\mathrm{C}$ & $\mathrm{O}$ & $\mathrm{H}$ & $\mathrm{N}$ \\
\hline HS & 50.04 & 43.21 & 5.89 & 0.43 \\
\hline WS & 48.72 & 44.51 & 5.74 & 0.33 \\
\hline
\end{tabular}

Information on the physicochemical properties of the materials used was presented by Kuśmierek and Świątkowski (2015a). In order to better examine the surface of the hazelnuts and walnuts shells, the water vapor adsorption isotherms were determined (Fig. 2 ), and on their basis the number of $\mathrm{H}_{2} \mathrm{O}$ primary adsorption centers was determined $\left(a_{0}\right)$ using Eq. 3,

$$
h / a=\left(1 / a_{0} c\right)-\left(1 h / a_{0}\right)
$$

where $h$ is the equilibrium relative pressure, $a$ is the adsorption $(\mathrm{mmol} / \mathrm{g}), c$ is the equation constant, and $a_{0}$ is the number of primary adsorption centers $(\mathrm{mmol} / \mathrm{g})$. 

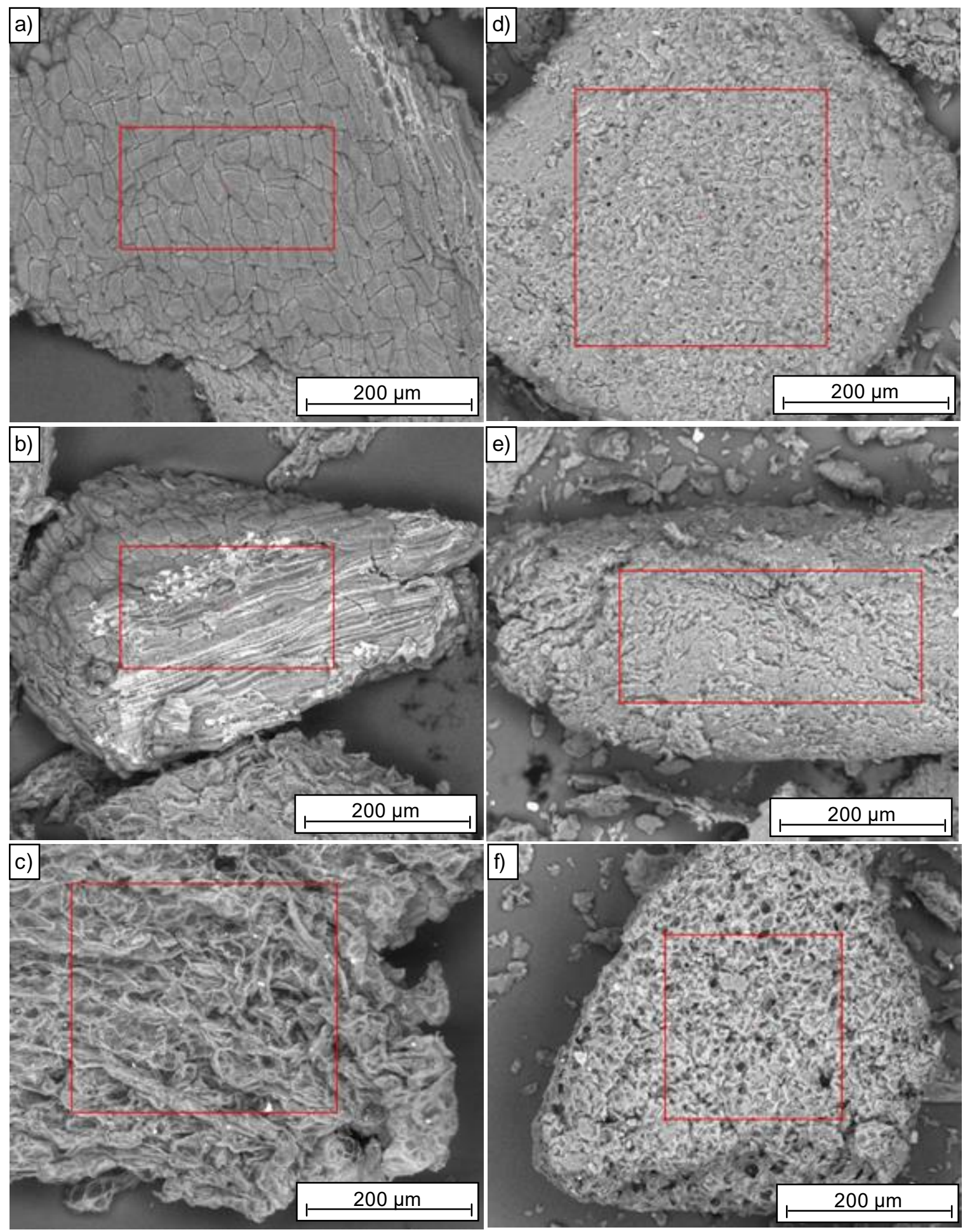

Fig. 1. SEM images of the hazelnut shells: a) external surface; b) cross-section; c) inner surface and walnut shells: d) external surface; e) cross-section; f) inner surface

A detailed procedure is described in Kuśmierek et al. (2019). The $a_{0}$ values allow the characterization of the degree of polarity of the adsorbent surface to estimate its hydrophilic or hydrophobic character. A slightly higher number of $\mathrm{H}_{2} \mathrm{O}$ primary adsorption centers obtained for the WS $(12.7 \mathrm{mmol} / \mathrm{g})$ in comparison to the HS $(11.9 \mathrm{mmol} / \mathrm{g})$ means the surface of the walnut shells displayed a slightly higher polarity. 


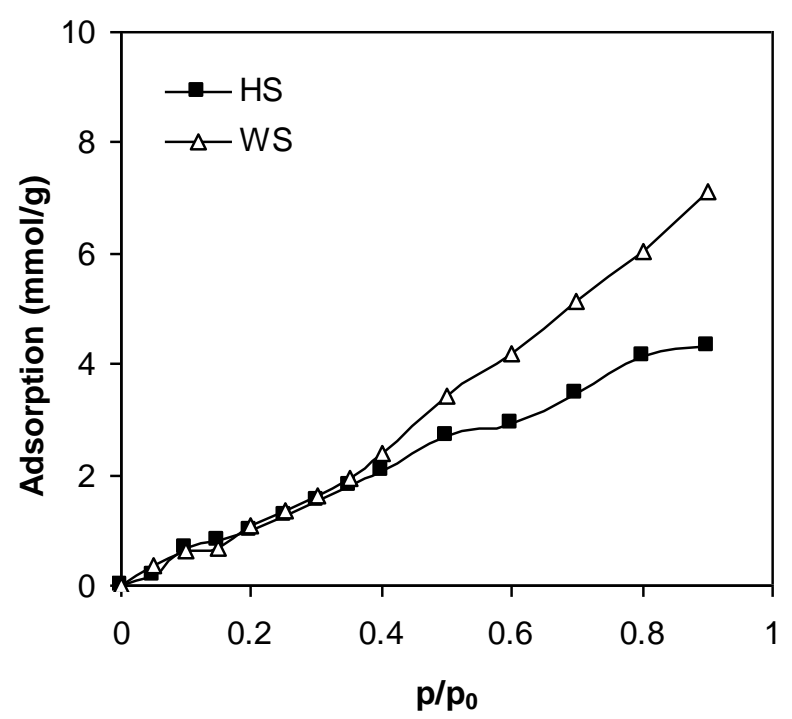

Fig. 2. Isotherms of water adsorption on the hazelnut and walnut shells

\section{Adsorption Studies}

The 4-CP adsorption isotherms on the walnut shells and the hazelnuts shells from $0.1 \mathrm{~mol} / \mathrm{dm}^{3}$ of $\mathrm{Na}_{2} \mathrm{SO}_{4}$ solution are shown in Fig. 3. The higher course of the experimental isotherm for HS compared to WS indicated a better adsorptive capacity of hazelnut shells in relation to 4-CP. In order to more accurately interpret the obtained results, the Langmuir (Eq. 4) and Freundlich isotherms (Eq. 5) were used for their description:

$$
\begin{aligned}
& q_{\mathrm{e}}=\left(q_{\mathrm{m}} b C_{e}\right) /\left(1+b C_{\mathrm{e}}\right) \\
& q_{\mathrm{e}}=K_{\mathrm{F}} C_{\mathrm{e}}{ }^{1 / \mathrm{n}}
\end{aligned}
$$

where $q_{\mathrm{m}}$ is the maximum adsorptive capacity ( $\mathrm{mmol} / \mathrm{g}$ ), $b$ is the constant of the Langmuir equation $\left(\mathrm{dm}^{3} / \mathrm{mmol}\right), K_{\mathrm{F}}$ is the constant of the Freundlich equation [equal to $\left.(\mathrm{mmol} / \mathrm{g})\left(\mathrm{dm}^{3} / \mathrm{mmol}\right)^{1 / \mathrm{n}}\right]$, and $n$ is the exponent of the equation.

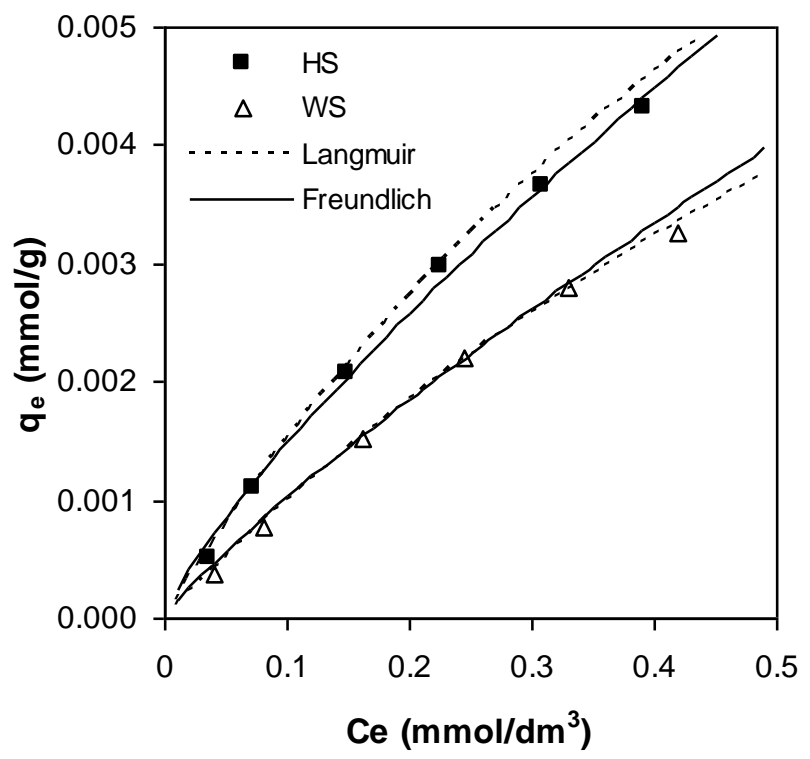

Fig. 3. Adsorption isotherms of 4-chlorophenol onto the hazelnut and walnut shells from 0.1 $\mathrm{mol} / \mathrm{dm}^{3}$ sodium sulphate solution 
The constants in Eqs. 4 and 5, shown in Table 3, were determined by curvilinear regression using Origin Pro 7.5 software. Higher $q_{\mathrm{m}}$ and $K_{\mathrm{F}}$ values were obtained for hazelnut shells. Therefore, HS seems to be a better sorbent in relation to 4-chlorophenol than WS probably due to their higher BET surface area in comparison to the walnut shells.

Table 3. The Langmuir and Freundlich Isotherm Equation Parameters for 4Chlorophenol Sorption on the Hazelnut and Walnut Shells

\begin{tabular}{|c|c|c|c|c|c|c|}
\hline \multirow{2}{*}{$\begin{array}{c}\text { Adsorbent } \\
\text { (modifier) }\end{array}$} & \multicolumn{3}{|c|}{ Langmuir } & \multicolumn{3}{|c|}{ Freundlich } \\
\cline { 2 - 7 } & $\begin{array}{c}q_{\mathrm{m}} \\
(\mathrm{mmol} / \mathrm{g})\end{array}$ & $\begin{array}{c}b \\
\left(\mathrm{dm}^{3} / \mathrm{mmol}\right)\end{array}$ & $\mathrm{R}^{2}$ & $\begin{array}{c}K_{\mathrm{F}} \\
{\left[(\mathrm{mmol} / \mathrm{g})\left(\mathrm{dm}^{3} / \mathrm{mmol}^{1 / \mathrm{n}}\right]\right.}\end{array}$ & $n$ & $\mathrm{R}^{2}$ \\
\hline $\mathrm{HS}$ & 0.0153 & 1.381 & 0.957 & 0.0108 & 1.258 & 0.996 \\
\hline $\mathrm{WS}$ & 0.0131 & 0.818 & 0.961 & 0.0091 & 1.175 & 0.997 \\
\hline
\end{tabular}

The adsorption capacities of HS $(0.0153 \mathrm{mmol} / \mathrm{g})$ and WS for 4-CP were essentially comparable with other low-cost adsorbents, including chitosan $(0.020 \mathrm{mmol} / \mathrm{g})$ (Li et al. 2009), hard coal (0.022 mmol/g) (Kuśmierek et al. 2016), and coke breeze $(0.023 \mathrm{mmol} / \mathrm{g})$ (Ahmaruzzaman and Sharma 2005).

The 4-CP adsorption was carried out according to the Freundlich model, for which higher values of correlation coefficients $\mathrm{R}^{2}(\geq 0.996)$ were obtained than for the Langmuir isotherm equation. The good fit obtained for the Freundlich isotherm suggests the heterogeneous nature of the adsorbents surface. The $K_{\mathrm{F}}$ values obtained for 4-CP sorption from solutions of sodium sulphate for the HS $\left[0.0108(\mathrm{mmol} / \mathrm{g})\left(\mathrm{dm}^{3} / \mathrm{mmol}\right)^{1 / \mathrm{n}}\right]$ and the WS $\left[0.0091(\mathrm{mmol} / \mathrm{g})\left(\mathrm{dm}^{3} / \mathrm{mmol}\right)^{1 / \mathrm{n}}\right]$ were higher than for the sorption of 4-CP from water $\left[0.008(\mathrm{mmol} / \mathrm{g})\left(\mathrm{dm}^{3} / \mathrm{mmol}\right)^{1 / \mathrm{n}}\right]$ (Kuśmierek and Świątkowski 2015a). Increased adsorption of 4-CP from inorganic salt solutions compared to water has previously been observed in the case of activated carbons (Hameed et al. 2008; Kuśmierek and Świątkowski 2015b). Generally, the adsorption of chlorophenols increases in the presence of an inorganic salt in solution, and it increases further with concentration and ionic strength of the solution. A similar trend was observed in the case of low-cost sorbents, which are wastes of the agri-food industry, on which 2,4,6-trichlorophenol (Kuśmierek et al. 2017a,b) and pentachlorophenol (Kuśmierek et al. 2018; Wierzbicka et al. 2019) were adsorbed.

The adsorption kinetics of the 4-CP onto hazelnut and walnut shells is shown in Fig. 4. In order to better understand the adsorption kinetics of 4-CP on nutshells, the pseudo first-order and pseudo second-order models were tested to fit and evaluate the experimental kinetic data. The pseudo first-order (Lagergren 1898) (Eq. 6) and pseudo second-order (Ho and McKay 1999) (Eq. 7) equations are given as:

$$
\begin{aligned}
& \log \left(q_{\mathrm{e}}-q_{\mathrm{t}}\right)=\log q_{\mathrm{e}}-k_{1} t / 2.303 \\
& t / q_{\mathrm{t}}=1 / k_{2} q_{\mathrm{e}}^{2}+t / q_{\mathrm{e}}
\end{aligned}
$$

where $k_{1}$ is the pseudo first-order adsorption rate constant $(1 / \mathrm{min})$ and $k_{2}$ is the pseudo second-order rate constant $(\mathrm{g} / \mathrm{mmol} \cdot \mathrm{min})$.

The calculated $k_{1}$ rate constants were $0.0228\left(R^{2}=0.960\right)$ and $0.0217\left(R^{2}=0.951\right)$ $1 /$ min for HS and WS, respectively. The pseudo second-order rate constants for HS and WS were found to be 9.043 and $8.868 \mathrm{~g} / \mathrm{mmol} \cdot \mathrm{min}$ with high correlation coefficients of 0.993 and 0.994 , respectively. The 4-CP was adsorbed slightly faster on the hazelnut shells than on the walnut shells. Based on higher correlation coefficients it can be concluded that the adsorption kinetics of 4-CP could well be approximated more favourably by pseudo second-order kinetic model rather than pseudo first-order kinetic equation. A good fitting 
of experimental data to pseudo second-order model suggests that the overall rate of adsorption process appears to be controlled by diffusion-related mechanisms.

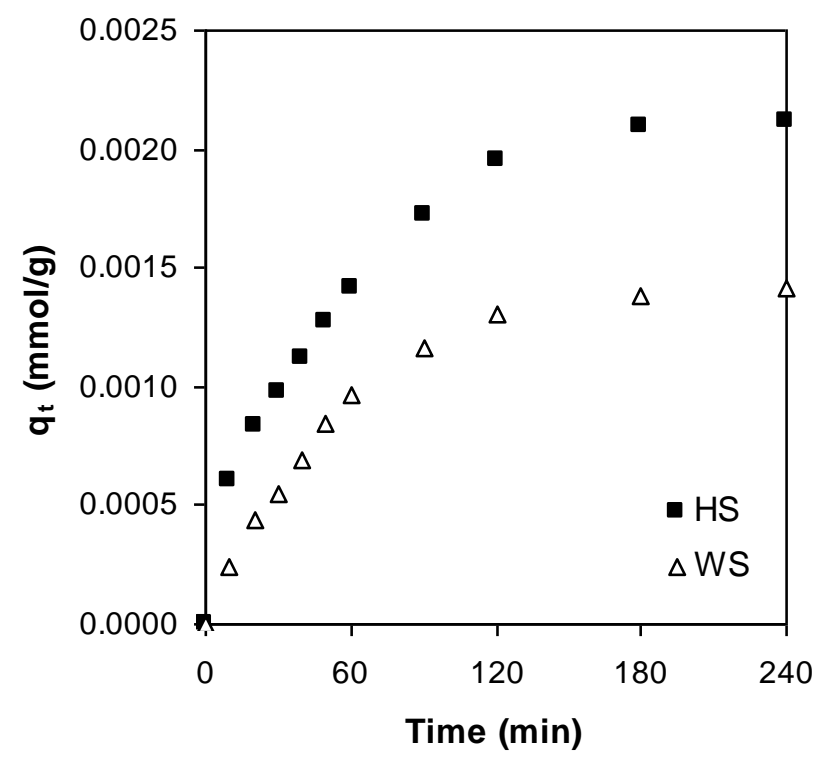

Fig. 4. Adsorption kinetics of 4-chlorophenol $\left(C_{0}=0.2 \mathrm{mmol} / \mathrm{dm}^{3}\right)$ onto the hazelnut and walnut shells from $0.1 \mathrm{~mol} / \mathrm{dm}^{3}$ sodium sulphate solution

\section{Electrochemical Studies}

The first stage of the electrochemical research was the determination of the electroactive surface of the tested electrodes (Apetrei et al. 2011; Ganesh and Kumara Swamy 2016). The electrochemical behavior of $2 \mathrm{mmol} / \mathrm{dm}^{3}$ of potassium ferrocyanide $\left[\mathrm{Fe}(\mathrm{CN})_{6}\right]^{3-/ 4-}$ in $1 \mathrm{mmol} / \mathrm{dm}^{3}$ of $\mathrm{KCl}$ was investigated using cyclic voltammetry $(\mathrm{CV})$. The CV voltammograms are shown in Fig. 5.

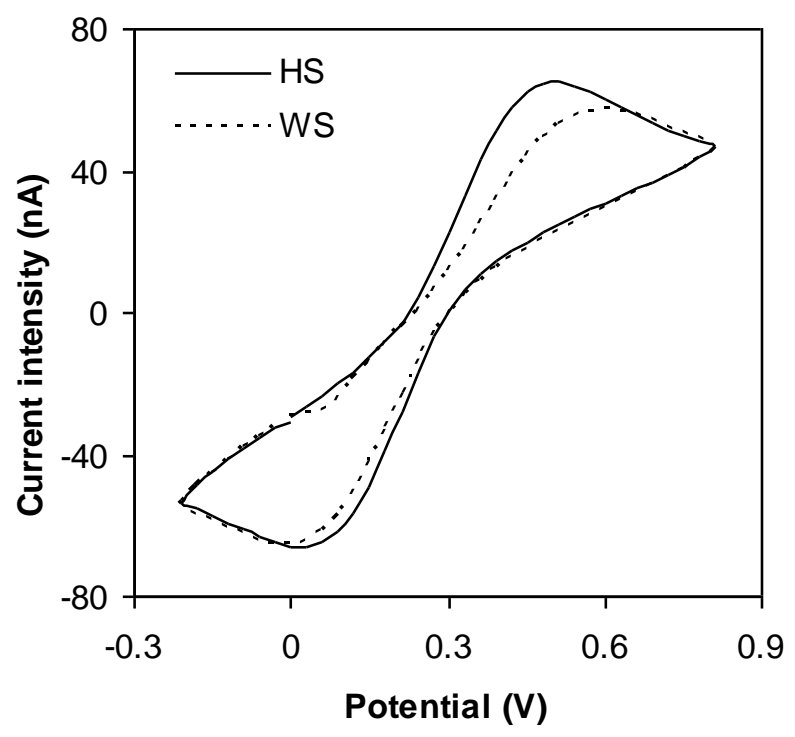

Fig. 5. The CV curves registered in $2 \mathrm{mmol} / \mathrm{dm}^{3}$ of $\left[\mathrm{Fe}(\mathrm{CN})_{6}\right]^{3-/ 4-}$ solution for CPEs modified with hazelnut and walnut shells $(10 \% \mathrm{~m} / \mathrm{m})$ 
The peak current for the reversible processes was determined from the RandlesSevcik Equation, as seen in Eq. 8,

$$
I_{p}=2.69 \times 10^{5} A D^{1 / 2} n^{3 / 2} v^{1 / 2} C
$$

where $A$ is the electrode surface $\left(\mathrm{cm}^{2}\right), n$ is the number of electrons participating in the reaction, $D$ is the diffusion coefficient, $C$ is the solution concentration $\left(\mathrm{mmol} / \mathrm{dm}^{3}\right)$, and $v$ is the scanning speed $(\mathrm{V} / \mathrm{s})$.

Based on the results obtained from the CV curve, the active surface of the electrode modified with the WS was calculated as $0.123 \mathrm{~cm}^{2}$, while for the electrode modified with the HS it was calculated as $0.165 \mathrm{~cm}^{2}$.

Next, the influence of the accumulation time on the peak current of the oxidation of 4-CP in a solution of $0.5 \mathrm{mmol} / \mathrm{dm}^{3}$ for the CPEs modified with both tested materials was determined. The peak current intensity was found to increase with the accumulation time until 2 min, after which it maintained a constant value (Fig. 6). In further studies the time of accumulation was assumed to be $2 \mathrm{~min}$.

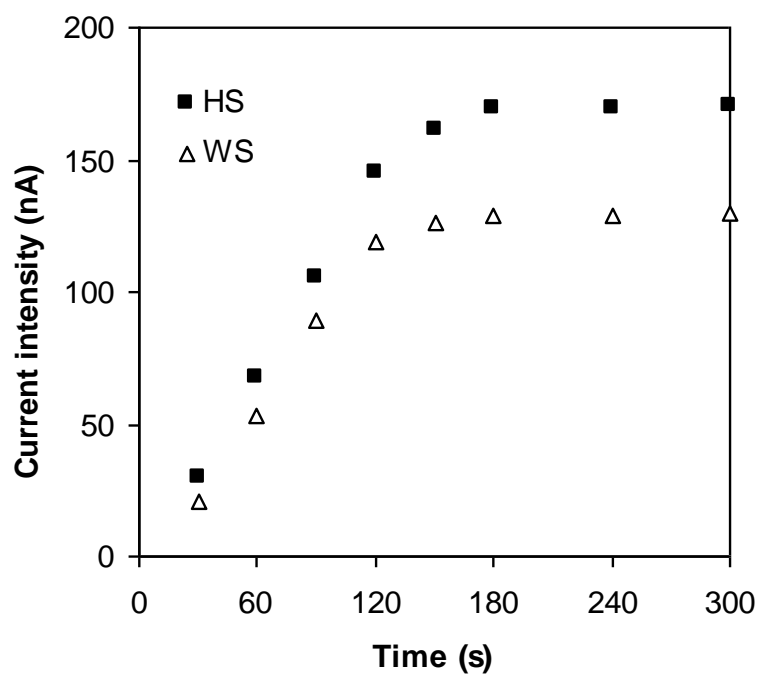

Fig. 6. Effect of accumulation time on the peak current

After accepting all measurement conditions, such as accumulation time and scanning speed, the CV curves were recorded for 4-CP solutions at concentrations of 0.1 to $0.5 \mathrm{mmol} / \mathrm{dm}^{3}$ using a $5 \%$ and $10 \%$ addition of the materials tested (CPE modifiers). Example voltammetric curves for five concentrations of 4-CP (from 0.1 to $0.5 \mathrm{mmol} / \mathrm{dm}^{3}$ ) recorded using electrodes containing 5 and 10\% addition of HS and WS are shown in Fig. 7. Based on the obtained results, via linear regression, equations of the calibration curves for individual electrodes were calculated and detection limits (LOD) were determined. The results are shown in Table 4.

Based on data obtained from the CV curves, an increase in peak current was found along with an increased addition of the modifier. This trend was observed for both modifiers. Even a small addition of the modifier clearly improved the electroanalytical properties of the electrode. In comparison to the unmodified electrode (graphite), all new electrodes showed a noticeable higher sensitivity in 4-CP detection. A two-fold increase in material addition (from 5 to $10 \mathrm{wt} \%$ ) resulted in a 1.5-fold increase in the height of the oxidation peak. The potential for oxidation occurred at about $0.75 \pm 0.05 \mathrm{~V}$. Generally, it can be concluded that better effects of the paste electrode modification were observed for 
the modifier (hazelnut shell) with a higher sorptive capacity in relation to 4-chlorophenol. The LODs observed for CPE modified with HS and WS were better than those observed for the CPEs modified with halloysite materials (Wierzbicka et al. 2019). As can be observed in Table 4, greatly increased sensitivity was achieved by including the nutshell material as carbon paste modifier. The increase can be explained as being due to a more open pore structure, allowing material to diffuse more rapidly in the electrode and adsorb more effective. Probably an important role is played here by the surface area of the nutshell materials, that was different (about two times greater) than for the main carbon paste material (graphite powder, $S_{\mathrm{BET}}=4 \mathrm{~m}^{2} / \mathrm{g}$ ). Similar observations regarding the importance of the surface area of CPE modifiers were in previous papers by the authors (Skrzypczyńska et al. 2016; Kuśmierek et al. 2017c).
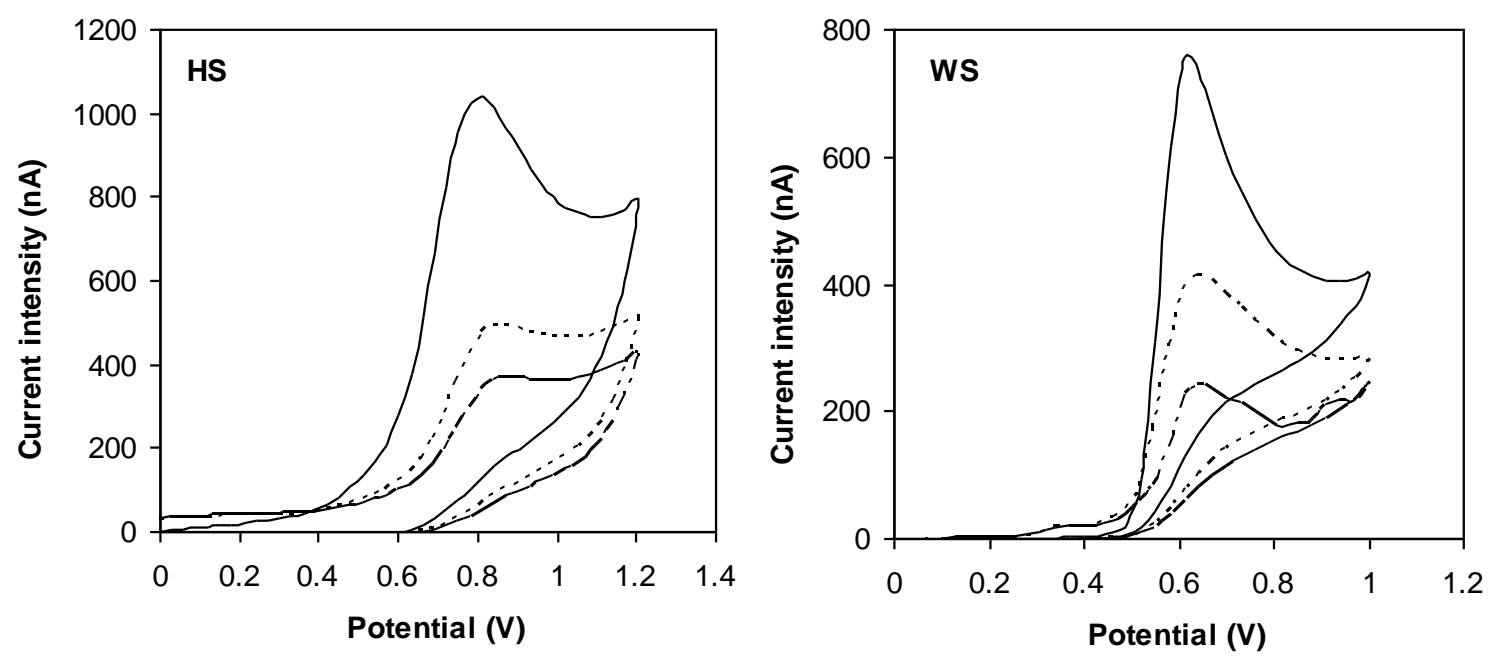

Fig. 7. The CV curves registered for $0.1,0.3$, and $0.5 \mathrm{mmol} / \mathrm{dm}^{3} 4-\mathrm{CP}$ for CPEs containing $10 \%$ of the modifier content

Table 4. Calibration Results for 4-CP Determination

\begin{tabular}{|c|c|c|c|c|}
\hline Material (modifier) & $\begin{array}{c}\text { Modifier Content } \\
(\%)\end{array}$ & $\begin{array}{c}\text { Equation of a Straight } \\
\text { (Calibration) Line }\end{array}$ & $\begin{array}{c}\mathrm{LOD} \\
\left(\mu \mathrm{mol} / \mathrm{dm}^{3}\right)\end{array}$ & $\mathrm{R}^{2}$ \\
\hline \multirow{2}{*}{$\mathrm{HS}$} & 5 & $y=1.180 x-0.036$ & 8.44 & 0.979 \\
\cline { 2 - 5 } & 10 & $y=1.980 x-0.056$ & 5.03 & 0.961 \\
\hline \multirow{2}{*}{ WS } & 5 & $y=0.990 x-0.047$ & 10.06 & 0.982 \\
\cline { 2 - 5 } & 10 & $y=1.261 x+0.074$ & 7.90 & 0.951 \\
\hline Only graphite & 0 & $y=0.155 x-0.004$ & 63.20 & 0.945 \\
\hline
\end{tabular}

\section{CONCLUSIONS}

1. The use of the graphite paste electrode with walnut shells and hazelnut shells as a modifier increased the current peak oxidation of 4-chlorophenol.

2. Even a small addition of the modifier (5\%) noticeably increased the possibilities of chlorophenol determination by means of carbon paste electrodes.

3. Materials with a higher sorptive capacity for the analyte (4-chlorophenol) were better modifiers. 


\section{ACKNOWLEDGMENTS}

The project was funded by a program of the Minister of Science and Higher Education entitled "Regional Initiative of Excellence" from 2019 to 2022 project number 025 / RID / 2018/19, with a financing amount of PLN 12,000,000.

\section{REFERENCES CITED}

Ahmaruzzaman, M., and Sharma, D. K. (2005). "Adsorption of phenols from wastewater," Journal of Colloid and Interface Science 287(1), 14-24. DOI: 10.1016/j.jcis.2005.01.075

Almeda, S., Nozal, L., Arce, L., and Valcárcel, M. (2007). "Direct determination of chlorophenols present in liquid samples by using a supported liquid membrane coupled in-line with capillary electrophoresis equipment," Analytica Chimica Acta 587(1), 97-103. DOI: 10.1016/j.aca.2007.01.035

Amiri, M., Ghaffari, S., Bezaatpour, A., and Marken, F. (2012). "Carbon nanoparticlechitosan composite electrode with anion, cation, and neutral binding sites:

Dihydroxybenzene selectivity," Sensors and Actuators B: Chemical 162(1), 194-200.

DOI: 10.1016/j.snb.2011.12.066

Apetrei, C., Apetrei, I. M., De Saja, J. A, and Rodriguez-Mendez, M. L. (2011). "Carbon paste electrodes made from different carbonaceous materials: application in the study of antioxidants," Sensors 11, 1328-1344. DOI: 10.3390/s110201328

Cao, J., Sun, T., and Grattan, K. T. V. (2014). "Gold nanorod-based localized surface plasmon resonance biosensors: A review," Sensors and Actuators B: Chemical 195, 332-351. DOI: 10.1016/j.snb.2014.01.056

Czaplicka, M. (2004). "Sources and transformations of chlorophenols in the natural environment," Science of The Total Environment 322(1-3), 21-39. DOI:

10.1016/j.scitotenv.2003.09.015

Dąbrowski, A., Podkościelny, P., Hubicki, Z., and Barczak, M. (2005). "Adsorption of phenolic compounds by activated carbon - A critical review," Chemosphere 58, 1049-1070. DOI: 10.1016/j.chemosphere.2004.09.067

Dar, R. A., Naikoob, G. A., Hassan, I. U., and Shaikh, A. M. H. (2016). "Electrochemical behavior of kaempferol and its determination in presence of quercetin employing multi-walled carbon nanotube modified carbon paste electrode," Analytical Chemistry Research 7, 1-8. DOI: 10.1016/j.ancr.2015.11.002

Das, P., Barbora, L., Das, M., and Goswami, P. (2014). "Highly sensitive and stable laccase based amperometric biosensor developed on nano-composite matrix for detecting pyrocatechol in environmental samples," Sensors and Actuators B: Chemical 192, 737-744. DOI: 10.1016/j.snb.2013.11.021

Devnani, H., and Satsangee, S. P. (2013). "Voltammetric trace determination of mercury using plant refuse modified carbon paste electrodes," Environmental Monitoring and Assessment 185(11), 9333-9342. DOI: 10.1007/s10661-013-3255-7

Elroby, A. (2015). "Chemically modified carbon paste electrodes for the determination of paroxetine hydrochloride in pharmaceutical preparations and biological fluids," International Journal of Chemistry 36(1), 1809-1817.

Fan, C., Li, N., and Cao, X. (2015). "Determination of chlorophenols in honey samples using in-situ ionic liquid-dispersive liquid-liquid microextraction as a pretreatment method followed by high-performance liquid chromatography," Food Chemistry 174, 
446-451. DOI: 10.1016/j.foodchem.2014.11.050

Gałuszka, A., Migaszewski, Z., and Namieśnik, J. (2013). “The 12 principles of green analytical chemistry and the SIGNIFICANCE mnemonic of green analytical practices," Trends in Analytical Chemistry 50, 78-84. DOI: 10.1016/j.trac.2013.04.010

Gan, T., Lv, Z., Sun, J., Shi, Z., and Liu, Y. (2016). "Preparation of graphene oxidewrapped carbon sphere@ @ilver spheres for high performance chlorinated phenols sensor," Journal of Hazardous Materials 302, 188-197. DOI: 10.1016/j.jhazmat.2015.09.061

Ganesh, P. S., Kumara Swamy, B. E. (2016). "Voltammetric resolution of catechol and hydroquinone at eosin Y film modified carbon paste electrode," Journal of Molecular Liquids 220, 208-215. DOI: 10.1016/j.molliq.2016.04.078

Gómez, Y., Fernández, L., Borrás, C., Mostany, J., and Scharifker, B. (2011). "Characterization of a carbon paste electrode modified with tripolyphosphatemodified kaolinite clay for the detection of lead," Talanta 85(3), 1357-1363. DOI: 10.1016/j.talanta.2011.06.014

Hameed, B. H., Chin, L. H., and Rengaraj, S. (2008). "Adsorption of 4-chlorophenol onto activated carbon prepared from rattan sawdust," Desalination 225(1-3), 185-198. DOI: 10.1016/j.desal.2007.04.095

Ho, Y. S., and McKay, G. (1999). "Pseudo-second-order model for sorption processes," Process Biochemistry 34, 451-465.

Khanikar, N., and Bhattacharyya, K. G. (2013). " $\mathrm{Cu}(\mathrm{II})$-kaolinite and $\mathrm{Cu}(\mathrm{II})-$ montmorillonite as catalysts for wet oxidative degradation of 2-chlorophenol, 4chlorophenol and 2,4-dichlorophenol," Chemical Engineering Journal 233, 88-97. DOI: 10.1016/j.cej.2013.08.018

Kuśmierek, K., and Świątkowski, A. (2015a). "Removal of chlorophenols from aqueous solutions by sorption onto walnut, pistachio and hazelnut shells," Polish Journal of Chemical Technology 17(1), 23-31. DOI: 10.1515/pjct-2015-0005

Kuśmierek, K., and Świątkowski, A. (2015b). "The influence of an electrolyte on the adsorption of 4-chlorophenol onto activated carbon and multi-walled carbon nanotubes," Desalination and Water Treatment 56(11), 2807-2816. DOI: 10.1080/19443994.2014.965221

Kuśmierek, K., Borucka, M., Świątkowski, A., and Dąbek, L. (2019). "Evaluation of different carbon materials in adsorption and solid-phase microextraction of 2,4,6trichlorophenol from water," Desalination and Water Treatment 157, 129-137. DOI: 10.5004/dwt.2019.24124

Kuśmierek, K., Dąbek, L., and Świątkowski, A. (2018). “Adsorptive removal of pentachlorophenol from water using agricultural and industrial wastes," Desalination and Water Treatment 117, 142-148. DOI: 10.5004/dwt.2018.22178

Kuśmierek, K., Idźkiewicz, P., Świątkowski, A., and Dąbek, L. (2017a). "Adsorptive removal of pentachlorophenol from aqueous solutions using powdered eggshell," Archives of Environmental Protection 43(3), 10-16. DOI: 10.1515/aep-2017-0029

Kuśmierek, K., Świątkowski, A., and Dąbek, L. (2017b). "Removal of 2,4,6trichlorophenol from aqueous solutions using agricultural waste as low-cost adsorbents," Environment Protection Engineering 43(4), 149-163. DOI: 10.5277/epe170412

Kuśmierek, K., Świątkowski, A., Skrzypczyńska, K., Błażewicz, S., and Hryniewicz, J. (2017c). "The effects of the thermal treatment of activated carbon on the phenols 
adsorption," Korean Journal of Chemical Engineering 34/4, 1081-1090. DOI: 10.1007/s 11814-017-0015-3

Kuśmierek, K., Zarębska, K., and Świątkowski, A. (2016). "Hard coal as a potential lowcost absorbent for removal of 4-chlorophenol from water," Water Science \& Technology 73(8), 2025-2030. DOI: 10.2166/wst.2016.046

Lagergren, S. (1898). "Theorie der sogenannten Adsorption geloester Stoffe," Vetenskapsakademiens Handlingar 24, 1-39.

Li, J. M., Meng, X. G., Hu, C. W., and Du, J. (2009). “Adsorption of phenol, pchlorophenol and $p$-nitrophenol onto functional chitosan," Bioresource Technology 100(3), 1168-1173. DOI: 10.1016/j.biortech.2008.09.015

Lin, S. H., and Juang, R. S. (2009). "Adsorption of phenol and its derivatives from water using synthetic resins and low-cost natural adsorbents: A review," Journal of Environmental Management 90, 1336-1349. DOI: 10.1016/j.jenvman.2008.09.003

Mojica, E. R. E., Vidal, J. M., Pelegrina, A. B., and Micor, J. R. L. (2007). "Voltammetric determination of lead (II) ions at carbon paste electrode modified with banana tissue," Journal of Applied Sciences 7(9), 1286-1292. DOI: 10.3923/jas.2007.1286.1292

Mukdasai, S., Butwong, N., Thomas, C., Srijaranai, S., and Srijaranai, S. (2016). “A sensitive and selective spectrophotometric method for 2-chlorophenol based on solid phase extraction with mixed hemimicelle magnetic nanoparticles," Arabian Journal of Chemistry 9(3), 463-470. DOI: 10.1016/j.arabjc.2014.12.023

Noorimotlagh, Z., Shahriyar, S., Darvishi Cheshmeh Soltanic, R., and Tajik, R. (2016). "Optimized adsorption of 4-chlorophenol onto activated carbon derived from milk vetch utilizing response surface methodology," Desalination and Water Treatment 57, 14213-14226. DOI: 10.1080/19443994.2015.1067830

Oliveira, T. M. B. F., Barroso, M. F., Morais, S., Araújo, M., Freire, C., Lima-Neto, P., Correia, A. N., Oliveira, M. B. P. P., and Delerue-Matos, C. (2014). "Sensitive bienzymatic biosensor based on polyphenoloxidases-gold nanoparticles-chitosan hybrid film-graphene doped carbon paste electrode for carbamates detection," Bioelectrochemistry 98, 20-29. DOI: 10.1016/j.bioelechem.2014.02.003

Saraji, M., and Ghani, M. (2015). "Hollow fiber liquid-liquid-liquid microextraction followed by solid-phase microextraction and in situ derivatization for the determination of chlorophenols by gas chromatography-electron capture detection," Journal of Chromatography A 1418, 45-53. DOI: 10.1016/j.chroma.2015.09.062

Şencan, A., Karaboyac1, M., and Kılıç, M. (2015). "Determination of lead(II) sorption capacity of hazelnut shell and activated carbon obtained from hazelnut shell activated with $\mathrm{ZnCl}_{2}$," Environmental Science and Pollution Research 22(5), 3238-3248. DOI: 10.1007/s11356-014-2974-9

Skrzypczyńska, K., Kuśmierek, K., and Świątkowski, A. (2016). "Carbon paste electrodes modified with various carbonaceous materials for the determination of 2,4dichlorophenoxyacetic acid by differential pulse voltammetry," Journal of Electroanalytical Chemistry 766, 8-15. DOI: 10.1016/j.jelechem.2016.01.025

Soto, M. L., Moure, A., Dominguez, H., and Parajo, J. C. (2011). "Recovery, concentration and purification of phenolic compounds by adsorption: A review," Journal of Food Engineering 105, 1-27. DOI: 10.1016/j.jfoodeng.2011.02.010

Tang, R., Dai, C., Li, C., Liu, W., Gao, S., and Wang, C. (2017). "Removal of methylene blue from aqueous solution using agricultural residue walnut shell: equilibrium, kinetic, and thermodynamic studies," Journal of Chemistry 2017, 1-10, Article ID 8404965. DOI: $10.1155 / 2017 / 8404965$ 
Wei, M., Tian, D., Liu, S., Zheng, X., Duan, S., and Zhou, C. (2014). “ $\beta$-Cyclodextrin functionalized graphene material: A novel electrochemical sensor for simultaneous determination of 2-chlorophenol and 3-chlorophenol," Sensors and Actuators B: Chemical 195, 452-458. DOI: 10.1016/j.snb.2014.01.035

Wierzbicka, E., Legocka, I., Skrzypczyńska, K., Świątkowski, A., and Kuśmierek, K. (2019). "Halloysite as a carbon paste electrode modifier for the detection of phenol compounds," International Journal of Electrochemical Science 14, 4114-412. DOI: 10.20964/2019.05.20

Zhou, Y., Zhang, L., and Cheng, Z. (2015). "Removal of organic pollutants from aqueous solution using agricultural wastes: A review," Journal of Molecular Liquids 212, 739762. DOI: 10.1016/j.molliq.2015.10.023

Article submitted: July 2, 2019; Peer review completed: September 3, 2019; Revised version received: November 1, 2019; Accepted: November 11, 2019; Published:

November 25, 2019.

DOI: 10.15376/biores.15.1.368-381 